\title{
A EXECUÇÃO DE SENTENÇAS ARBITRAIS CONTRA ESTADOS ESTRANGEIROS SEGUNDO A CONVENÇÃO DE NOVA YORK DE 1958 E A CONVENÇÃO DE WASHINGTON DE 1965
}

Isabela Piacentini de Andrade ${ }^{1}$

\section{RESUMO}

A execução de sentenças arbitrais proferidas contra Estados estrangeiros esbarra normalmente em dois tipos de dificuldades. A primeira é relativa ao reconhecimento da sentença pelas jurisdições nacionais, sinônimo de controle interno da validade da sentença. A segunda é a execução material dos bens do Estado estrangeiro, pois é comum que as legislações nacionais atribuam a este uma imunidade de execução sobre sua propriedade. Estas duas questões foram tratadas diferentemente pela Convenção de Nova York de 1958 sobre o Reconhecimento e a Execução de Sentenças Arbitrais Estrangeiras e pela Convenção de Washington de 1965 para a Resolução de Disputas relativas a Investimentos entre Estados e Nacionais de Outros Estados. O artigo faz um paralelo entre ambas as Convenções, exemplificando seu uso através da jurisprudência.

\section{ABSTRACT}

The enforcement of arbitral awards against foreign States normally faces two sorts of difficulties. The first one concerns the recognition of the award by national courts, which implies an internal control of its validity. The second difficulty is to pursue the collection of the State's assets: it is common that national legislations grant the foreign State immunity from execution. These two issues are treated differently by the New York Convention on the Recognition and Enforcement of Foreign Arbitral Awards (1958) and by the Washington Convention on the Settlement of Investment Disputes between

1 Graduada em Direito pela UFPR. Mestranda em Direito Internacional Público pela Universidade de Paris II.

Revista Brasileira de Direito Internacional, Curitiba, v.2, n.2, jul./dez.2005 
States and Nationals of Other States (1965). This article compares both conventions and includes case law.

\section{INTRODUÇÃO}

A eficácia de um sistema de arbitragem é avaliada pela possibilidade de executar a sentença arbitral contra a parte condenada. Afinal, de que vale obter uma sentença favorável se ela não pode ser cumprida? Concebida como modo alternativo à solução de litígios através da justiça estatal, a arbitragem propugna pela execução voluntária do laudo pelas partes; na ausência do cumprimento espontâneo, entretanto, será necessário fazer uso desta mesma justiça estatal para obter a execução forçada da sentença. Nesse sentido, é importante que o sistema preveja mecanismos efetivos para viabilizar a execução. Esta tarefa é especialmente difícil quando se trata de um laudo arbitral condenando um Estado estrangeiro.

Se um Estado "A" é condenado numa arbitragem internacional e não cumpre o laudo espontaneamente, a parte vencedora poderá intentar a execução de bens que este Estado "A" possua no território de um Estado "B". Para tanto, ela deverá primeiramente obter dos tribunais internos de " $\mathrm{B}$ " 0 reconhecimento (exequatur) de sua sentença internacional para, num segundo momento, requerer a penhora dos bens do Estado "A" localizados no território de "B" (execução propriamente dita).

Em ambas as fases o demandante se depara com dificuldades, que podem culminar na frustração do seu objetivo. Para conseguir 0 reconhecimento, a sentença deverá em regra passar por um controle prévio dos tribunais internos, a fim de avaliar sua regularidade formal e a compatibilidade com eventuais leis nacionais sobre a matéria. Este controle representa uma interferência interna certamente indesejável para o credor cujo direito já foi reconhecido por uma arbitragem internacional. Obtido o reconhecimento, outra grande dificuldade deve ser enfrentada quando se passa à execução propriamente dita da sentença: o Estado estrangeiro goza da chamada imunidade de execução, segundo a qual os bens que ele possui 
no território do Estado "B" são protegidos contra medidas executórias, não podendo ser penhorados.

Feitos estes esclarecimentos iniciais a fim de situar a problemática do artigo, passaremos ao estudo dos sistemas de execução de sentenças arbitrais contra Estados estrangeiros previstos por duas convenções internacionais de ampla adesão em nível mundial: a Convenção de Nova York de 1958 e a Convenção de Washington de $1965^{2}$. Ambos os sistemas são ilustrados por uma jurisprudência internacional que visa a exemplificar a aplicação prática dos respectivos procedimentos executórios por diversas ordens jurídicas internas.

A Convenção de Nova York já é bem conhecida no Brasil pelos estudiosos da arbitragem internacional, diferentemente da Convenção de Washington. Enquanto que a primeira - a Convenção sobre o Reconhecimento e a Execução de Sentenças Arbitrais Estrangeiras feita em Nova York, em 10 de junho de 1958 - passou a integrar o ordenamento jurídico nacional através do Decreto 4.311, de 23 de julho de 2002, a segunda não foi ratificada pelo Brasil, o que de certa forma explica o relativo desinteresse interno pelo seu estudo.

A Convenção de Washington de $1965^{3}$ criou o Centro Internacional para a Resolução de Disputas Relativas a Investimentos (CIRDI, ou ICSID em inglês), instituição arbitral destinada a julgar conflitos entre investidores estrangeiros e Estados receptores de investimento. As sentenças proferidas pelo CIRDI passam por um procedimento de execução diferenciado nas ordens internas, e as peculiaridades deste sistema constituem uma inovação marcante no âmbito da arbitragem internacional. Assim, ainda que o sistema de execução das sentenças CIRDI não seja aplicável na nossa ordem jurídica interna, sua potencial contribuição à evolução da arbitragem internacional torna-o digno de estudo.

\footnotetext{
${ }^{2}$ A Convenção de Nova York de 1958 conta com 137 Estados partes, e a Convenção de Washington com 143. Fontes: www.un.org e www.worldbank.org/icsid.

${ }_{3}$ Convenção para a Resolução de Disputas relativas a Investimentos entre Estados e Nacionais de Outros Estados, celebrada em Washington em 18 de março de 1965, entrada em vigor em 14 de outubro de 1966. Disponível no site: http://www.worldbank.org/icsid/.
}

Revista Brasileira de Direito Internacional, Curitiba, v.2, n.2, jul./dez.2005 


\section{A EXECUÇÃO "CLÁSSICA" DE SENTENÇAS ARBITRAIS CONTRA ESTADOS ESTRANGEIROS}

\subsection{O PROCESSO DE EXECUÇÃO SEGUNDO A CONVENÇÃO DE} NOVA YORK DE 1958

O reconhecimento e a execução de sentenças arbitrais estrangeiras foi inicialmente regido em nível internacional por convenções bilaterais. Em seguida, marcando uma primeira etapa de um tratamento multilateral da questão, foram concebidos o Protocolo de Genebra de 1923 e a Convenção de Genebra de 1927. O interesse prático por esses instrumentos diminuiu sobremaneira após o advento da Convenção de Nova York de 1958, cujas disposições representaram um grande avanço em relação aos acordos de Genebra, em especial no tocante à eliminação do "duplo exequatur" e atribuição do ônus da prova à parte que impugna o reconhecimento ou execução da sentença. Assim, a Convenção de Nova York constitui hoje o principal tratado multilateral sobre o reconhecimento e execução de sentenças estrangeiras.

A Convenção estabelece que as sentenças arbitrais estrangeiras são obrigatórias para os Estados signatários, os quais se comprometem a executála segundo seus procedimentos previstos em âmbito interno, respeitando-se as demais condições estabelecidas pela Convenção (artigo III). Para obter 0 reconhecimento e a execução, a parte demandante deve fornecer os originais ou cópias autenticadas da sentença e da convenção arbitrais (artigo IV).

Em seguida, são previstas as hipóteses segundo as quais 0 reconhecimento ou execução podem ser negados pelas jurisdições internas. Autoriza-se, assim, o exercício de uma sorte de controle prévio sobre as sentenças arbitrais estrangeiras.

A Convenção distingue duas séries de objeções que podem ser opostas ao reconhecimento e execução da uma sentença. As primeiras são previstas pelo artigo V, § 1 e ocorrem quando (a) a convenção de arbitragem é inválida ou há incapacidade das partes, (b) há violação do princípio do 
contraditório, (c) a sentença extrapola os termos da convenção de arbitragem, (d) há irregularidade na composição do tribunal arbitral ou vícios de procedimento, ou (e) a sentença arbitral ainda não é obrigatória. As objeções devem ser invocadas e provadas pela parte que se opõe ao reconhecimento ou à execução da sentença.

A segunda série de objeções está contida no artigo $V, \S 2$. Tais objeções podem ser invocadas pelo próprio juiz nacional, e referem-se (a) à arbitrabilidade do litígio e (b) à ordem pública. Diferentemente da primeira série de objeções, relativa a aspectos formais da sentença, as objeções do artigo V, $\S 2$ dizem respeito a questões internas do Estado onde a sentença deve ser executada, e a existência ou não de uma violação à ordem pública estatal ou a inarbitrabilidade da questão dependerão das disposições contidas na legislação nacional de cada país onde se pleiteiam o reconhecimento e a execução.

Esta gama de objeções das quais podem se servir as jurisdições internas para recusar o reconhecimento e a execução de uma sentença arbitral estrangeira é fonte de grandes confusões e dificuldades, especialmente quando se trata de uma sentença proferida contra um Estado. A jurisprudência apresentada a seguir ilustra bem tais problemas, mostrando como a existência de um controle prévio pode causar transtornos inimagináveis aos credores, levando sentenças a ter de passar por peripécias internacionais. Notar-se-á também que os tribunais internos não estabelecem uma separação nítida entre as fases de reconhecimento e execução, ambas podendo ser contestadas com base no artigo $\mathrm{V}$, parágrafos 1 e 2 .

\subsection{JURISPRUDÊNCIA}

(a) Société Européenne d'Etudes et d'Entreprises (SEEE) $\mathrm{X}$ lugoslávia

A SEEE era uma empresa francesa que firmou um contrato com a lugoslávia para a construção de uma linha férrea. Em razão da Segunda Guerra Mundial, entretanto, este país cessou de efetuar os pagamentos 
contratuais devidos. Passada a guerra, a França e a lugoslávia negociaram em 1950 um acordo que oferecia à SEEE uma compensação em razão do descumprimento do contrato, compensação esta que a SEEE aceitou. Mas alguns anos depois, a empresa considerou que a indenização recebida não era suficiente e resolveu então submeter a questão à arbitragem. ${ }^{4}$

Uma sentença arbitral condenando a lugoslávia foi proferida por dois árbitros na Suíça, país onde em seguida a SEEE solicitou o reconhecimento da sentença. A corte suíça, todavia, recusou-se a fazê-lo porque, segundo ela, a sentença não poderia ser considerada suíça já que foi proferida por dois árbitros e não três como previa a lei deste país. Em conseqüência, a sentença foi devolvida às partes e se tornou a partir daí uma sentença "anacional".

A SEEE decidiu então pedir o reconhecimento da sentença na Holanda. Mas lá também, a Corte de Apelação da Haia rejeitou o reconhecimento, pois a sentença tinha se tornado "anacional" segundo a corte suíça. Em sede de recurso, entretanto, a Corte Suprema entendeu que a Convenção de Nova York se aplicava a sentenças anacionais e reenviou a questão à Corte de Apelação. Esta, numa segunda decisão, novamente rejeitou o reconhecimento da sentença, mas desta vez sustentando que ela era contrária à ordem pública. Julgando um outro recurso, a Corte Suprema holandesa decidiu por fim recusar o reconhecimento da sentença baseando-se no artigo $V(1)(e)^{5}$ da Convenção de Nova York pois, devido às decisões das cortes suíças, o laudo não seria mais executável nem na Suíça nem na Holanda. $^{6}$

A SEEE também solicitou o reconhecimento do laudo na França e neste país, finalmente, o obteve. A etapa seguinte consistiria na execução da sentença, mas tal objetivo tornou-se um outro pesadelo. A empresa pediu a penhora de empréstimos feitos à lugoslávia pelo Banco Mundial para o desenvolvimento econômico deste país. Mas devido a objeções da lugoslávia,

\footnotetext{
${ }^{4}$ DELAUME, G. SEEE v. Yugoslavia: Epitaph or Interlude?, Journal of International Arbitration, 1987, p. 26-27.

${ }^{5}$ Este artigo prevê a recusa do reconhecimento e da execução se "a sentença ainda não se tornou obrigatória para as partes ou foi anulada ou suspensa por autoridade competente do país em que, ou conforme a lei do qual, a sentença tenha sido proferida."

DELAUME, G. Reflections on the effectiveness of international arbitral awards. Journal of international arbitration, 1995, p. 28-29.
}

Revista Brasileira de Direito Internacional, Curitiba, v.2, n.2, jul./dez.2005 
do governo francês e do Banco Mundial, o exequatur foi revogado pelo Tribunal de Paris pois seria contrário à ordem pública: o Tribunal alegou que desconhecia a existência do acordo firmado entre a França e a lugoslávia em 1950. A Corte de Apelação confirmou esta decisão, diferentemente da Corte de Cassação, que a cassou e que reenviou o caso a outra Corte de Apelação, em Orleans. Esta Corte, por sua vez, recusou reconhecimento à sentença pois esta conteria um grande erro de cálculo do montante devido à SEEE, o que constituiria uma ofensa à ordem pública francesa. A Corte de Cassação anulou também esta decisão e enviou o caso à Corte de Apelação de Rouen. A Corte de Rouen concedeu o exequatur considerando que a sentença poderia ser reconhecida segundo a Convenção de Nova York. A Corte de Cassação manteve esta decisão e ordenou a penhora de valores que seriam devidos à lugoslávia por instituições financeiras e pela Air France. O Tribunal de Grande Instância de Paris, todavia, suspendeu a penhora que havia sido praticada contra a Air France pois o montante de taxas de sobrevôo em questão caracterizar-se-ia como um exercício pela lugoslávia de suas prerrogativas próprias de soberania nacional e internacional ${ }^{7}$, e beneficiariam portanto de imunidade de execução. As demais demandas de suspensão de penhora foram rejeitadas pelo Tribunal pois só seriam recebíveis na presença de bens corpóreos ou incorpóreos penhorados, momento no qual a lugoslávia poderia então justificar concretamente uma ameaça prejudicial à sua imunidade de execução ${ }^{8}$.

\section{(b) Libyan American Oil Company (LIAMCO) X Líbia}

Em 12 de abril de 1977, em Genebra, a empresa americana LIAMCO obteve, de um árbitro único, uma sentença que condenou o Estado da Líbia a pagar uma indenização devido ao inadimplemento de certas obrigações contratuais. Devido à recusa da Líbia de resolver a questão amigavelmente, a

\footnotetext{
${ }^{7}$ République de Yougoslavie c/ Société européenne d'études et d'entreprises (S.E.E.E.), Air France et autres, Tribunal de grande instance de Paris (ord. référé), 3 de julho de 1985, Revue de l'arbitrage, 1985, p. 717.

${ }^{8}$ Idem, ibidem.
}

Revista Brasileira de Direito Internacional, Curitiba, v.2, n.2, jul./dez.2005 
LIAMCO decide acionar tribunais de vários países onde a Líbia detinha bens para obter a execução da sentença. ${ }^{9}$ Quatro execuções foram iniciadas: na França, na Suíça, na Suécia e nos Estados Unidos. Com exceção da Suíça, nenhum dos procedimentos chegou a termo porque as partes concluíram transações amigáveis. Entretanto, o estudo das aventuras pelas quais passou esta sentença são também um bom exemplo das dificuldades práticas enfrentadas quando se intenta a execução de uma sentença arbitral contra um Estado estrangeiro.

Na França, o Tribunal de Grande Instância de Paris concedeu, em 7 de fevereiro de 1979, o exequatur após constatar que a sentença não continha nada de contrário às leis e à ordem pública e apresentava todas as aparências de regularidade formal. A pedido da LIAMCO, vinte e nove ordens de penhora foram executadas, provocando a reação da Líbia que dirigiu uma nota de protesto ao Quai d'Orsay denunciando a violação das imunidades tradicionalmente reconhecidas aos Estados soberanos. Em resposta, LIAMCO argumentou que a imunidade de execução não é absoluta e que portanto seria necessário determinar a natureza dos bens penhorados. Em 5 de março 0 Tribunal ordenou o cancelamento das penhoras, mas concedeu igualmente a medida solicitada pela empresa. ${ }^{10} \mathrm{Um}$ acordo entre as partes colocou termo à questão.

$\mathrm{Na}$ Suíça, a LIAMCO obteve a penhora de bens da Líbia em seis bancos de Zurique. Todavia, o Tribunal Federal suíço declarou nulas as ordens de penhora pois não haveria uma relação suficiente entre o caso e a Suíça. ${ }^{11}$

$\mathrm{Na}$ Suécia, a Svea Court de Estocolmo concedeu o exequatur sob o fundamento de que a Líbia havia aceito uma cláusula compromissória e portanto renunciado à sua imunidade de jurisdição estatal, apesar de dois dos cinco juízes entenderem que a cláusula não implicava a renúncia. A transação

\footnotetext{
${ }^{9}$ RAMBAUD, P. Les suites d'un différend pétrolier: l'affaire Liamco devant le juge français. Annuaire Français de Droit International, 1979, p. 821-822. ${ }^{10}$ Idem, p. 823.

${ }^{11}$ LALIVE, J-F. Quelques observations sur l'immunité d'exécution des Etats et l'arbitrage international. In: International law at a time of perplexity: essays in honour of Shabtai Rosenne. Dordrecht/ Boston/ London: Martinus Nijhoff, 1989, p. 377.
}

Revista Brasileira de Direito Internacional, Curitiba, v.2, n.2, jul./dez.2005 
concluída pelas partes depois impediu a Corte Suprema de se pronunciar sobre o tema.

Nos Estados Unidos, a District Court igualmente julgou que a Líbia renunciou à sua imunidade de jurisdição ao aceitar uma cláusula arbitral. Entretanto, a Corte recusou a execução da sentença sob fundamento do artigo V §2 (a) da Convenção de Nova York ${ }^{12}$, considerando que o litígio não era arbitrável nos Estados Unidos devido à doutrina do Act of State. Esta decisão foi duramente criticada e o próprio governo americano atuou como amicus curiae em sede do recurso de apelação. Apesar da transação concluída entre a LIAMCO e a Líbia, a Court of Appeals, numa decisão não motivada, anulou aquela da District Court, aceitando assim a intervenção dos amici curiae da LIAMCO. $^{13}$

Os dois casos citados demonstram que, na prática, as hipóteses previstas pela Convenção de Nova York para a recusa do reconhecimento ou da execução de uma sentença (artigo $\mathrm{V}$ ) suscitam muitas controvérsias no seio das jurisdições nacionais, conduzindo a interpretações divergentes de cortes de um mesmo país e variando de Estado para Estado em razão da diversidade dos direitos internos. A possibilidade de realização de um controle prévio, seja a pedido da parte impugnante ou de ofício, representa indiscutivelmente um obstáculo à execução, podendo retardá-la ou mesmo impedi-la. O recurso ao direito interno, especialmente à noção maleável de "ordem pública", é o exemplo mais evidente.

\footnotetext{
${ }^{12}$ Artigo que dita que um Estado pode recusar o reconhecimento e execução de uma sentença quando o litígio não é passível de arbitragem segundo sua lei interna.

${ }^{3}$ BROTONS, A. R. La reconnaissance et l'exécution des sentences arbitrales étrangères. Recueil des cours, 1984, p. 342, note 262.
}

Revista Brasileira de Direito Internacional, Curitiba, v.2, n.2, jul./dez.2005 


\section{A EXECUÇÃO DAS SENTENÇAS ARBITRAIS DO CIRDI}

\subsection{O PROCESSO DE EXECUÇÃO SEGUNDO A CONVENÇÃO DE WASHINGTON DE 1965}

A criação do CIRDI pela Convenção de Washington de 1965 foi uma resposta à busca dos investidores estrangeiros por um organismo neutro onde suas diferenças com o Estado receptor de seus investimentos pudessem ser resolvidas com imparcialidade, fora das jurisdições nacionais. Em termos gerais, a Convenção de Washington proíbe a interferência do juiz nacional na arbitragem CIRDI, que é autônoma. Entretanto, caso os Estados condenados não respeitem espontaneamente a sentença, o recurso às jurisdições nacionais é inevitável para obter-se coercitivamente seu cumprimento. Esta hipótese foi cuidadosamente tratada pela Convenção, que soube limitar os poderes do juiz interno relativos ao reconhecimento das sentenças do CIRDI, inovando em relação ao regime previsto pela Convenção de Nova York.

A Convenção de Washington prevê normas sobre 0 reconhecimento e a execução das sentenças CIRDI nos seus artigos 53, 54 et 55. Estas disposições conferem ao seu sistema de execução um caráter único, conforme veremos a seguir.

Já de início, é importante perceber que, diferentemente da Convenção de Nova York, na Convenção de Washington pode-se notar uma distinção clara entre as fases de reconhecimento e de execução da sentença arbitral.

No tocante ao reconhecimento, a Convenção de Washington estabelece o princípio da eficácia automática das sentenças nas ordens internas de todos os Estados signatários. ${ }^{14}$ Não cabem objeções relativas à defeitos formais da sentença ou do procedimento arbitral nem objeções baseadas em direitos nacionais.

É uma obrigação de todos os Estados signatários reconhecer e executar as sentenças arbitrais do CIRDI como se fossem julgamentos definitivos proferidos dentro de seu próprio território (art. 54 § 1). Proferida pelo

${ }^{14}$ GIARDINA, A. L'exécution des sentences du Centre international pour le règlement des différends relatifs aux investissements. Revue critique de droit international privé, 1982, p. 276.

Revista Brasileira de Direito Internacional, Curitiba, v.2, n.2, jul./dez.2005 
tribunal CIRDI, a sentença é obrigatória para as partes e não pode ser contestada nas cortes nacionais. Recursos são admitidos somente dentro do próprio sistema CIRDI, e são aqueles previstos pela própria Convenção (art. 52). Assim, em caso de vícios formais (constituição viciada do tribunal arbitral, excesso de poder deste ou corrupção de árbitros, vícios no procedimento, etc.), as partes devem solicitar ao próprio CIRDI a anulação da sentença.

O processo de reconhecimento nas ordens internas é simples: basta apresentar uma cópia da sentença certificada pelo secretário geral do CIRDI ao tribunal ou à autoridade interna competente (art. 54 § 2).

Assim, os tribunais internos são obrigados a reconhecer a sentença pela simples apresentação de sua cópia certificada. Esta é a única condição de reconhecimento. A parte executada não pode apresentar nenhuma objeção tais como as previstas pela Convenção de Nova York quanto a aspectos formais da sentença ou referentes a direitos internos. Conseqüentemente, os juízes nacionais não podem recusar o reconhecimento de uma sentença CIRDI com fundamento na sua lei interna (violação da ordem pública, inarbitrabilidade da disputa, doutrina do Act of State, etc.) ou em vícios formais (eventuais motivos de anulação devem ser levados diretamente ao CIRDI). A única ação possível é a verificação da autenticidade da sentença.

Desta forma, a Convenção de Washington põe fim aos problemas e confusões que surgiam na fase de reconhecimento das sentenças como vimos na jurisprudência supracitada, na medida em que ela não admite nenhuma hipótese de recusa do reconhecimento, que é automático. As jurisdições internas são obrigadas a aceitar a sentença CIRDI e não podem contestá-la.

Depois do reconhecimento, a sentença é suscetível de ser executada. Passa-se à segunda fase, a execução propriamente dita. É então necessário encontrar bens do Estado condenado que possam satisfazer à obrigação devida.

Se para reconhecer a sentença os Estados não podem fazer uso de suas leis internas, a situação é diferente quando se trata da execução. A Convenção de Washington prevê que esta é regida pela legislação relativa à 
execução de sentenças em vigor no Estado onde ela é solicitada (artigo $54 \S$ $3)$.

A diferença de tratamento entre o reconhecimento e a execução pode ser explicado, segundo CARIAS-BORJAS ${ }^{15}$, pois cada uma das fases tem uma natureza diversa, gerando problemas específicos. O procedimento de execução, diferentemente do de reconhecimento, possibilita a utilização de medidas coercitivas dentro do território de um Estado. Não se pode exigir de um Estado signatário a adoção de medidas de execução por suas jurisdições que ele não dispõe. ${ }^{16}$ Presume-se que não seria aceitável exigir de um Estado signatário um tratamento mais favorável à execução de uma sentença CIRDI que à execução de seus próprios julgamentos internos. ${ }^{17}$

No que diz respeito à execução, portanto, a Convenção deixa aos Estados signatários a liberdade de determinar se irão e como irão realizar a execução de bens dos Estados estrangeiros. Conseqüentemente, o sucesso do procedimento executório de uma sentença CIRDI depende da legislação do Estado onde a execução é intentada.

Dentre as previsões que podem conter as legislações internas sobre o procedimento de execução de sentenças contra Estados estrangeiros, a mais marcante é indubitavelmente a imunidade de execução. $O$ artigo 55 da Convenção admite expressamente o emprego desta imunidade quando ela é prevista pelo direito nacional. Conforme mencionamos, esta imunidade impossibilita a execução dos bens do Estado estrangeiro, representando assim um obstáculo à satisfação dos direitos do credor aparentemente intransponível. Esta imunidade, entretanto, sofreu relativizações ao longo dos anos, à medida em que os Estados passaram a participar de atividades comerciais e negociar com os particulares. Assim, as leis internas e a jurisprudência foram aos poucos se modificando e o princípio de imunidade de execução deixou de ser absoluto quando os bens estatais têm uma destinação privada ou comercial. A

\footnotetext{
${ }^{15}$ CARIAS-BORJAS, S. Recognition and enforcement of ICSID awards: the decision of the French Cour de cassation in SOABI v. Senegal. American review of international arbitration, vol. 2, n. 3, 1991, p. 354-372.

${ }^{16}$ Em alguns Estados, por exemplo, não é possível executar uma obrigação de fazer, motivo pelo qual segundo o artigo 54 (1) somente a execução de obrigações pecuniárias se impõe.

${ }^{17}$ CARIAS-BORJAS, p. 359.
}

Revista Brasileira de Direito Internacional, Curitiba, v.2, n.2, jul./dez.2005 
diversidade das práticas nacionais e a dificuldade de provar a destinação pública ou privada do bem faz todavia com que a execução contra um Estado estrangeiro continue a ser uma tarefa difícil. ${ }^{18}$ É o que confirma a jurisprudência apresentada em seguida, a qual mostra também que os tribunais internos têm ainda a tendência - certamente um reflexo da prática da Convenção de Nova York -, de querer exercer controles prévios na fase de reconhecimento das sentenças CIRDI e de confundir esta fase com a de execução.

\subsection{JURISPRUDÊNCIA}

(a) Benvenuti \& Bonfant S.A.R.L. X República Popular do Congo

Benvenuti \& Bonfant era uma empresa italiana que obteve uma sentença favorável do $\mathrm{CIRDI}^{19}$ contra o Congo e solicitou sua execução na França. O Tribunal de Grande Instância de Paris concedeu o exequatur mas sob o fundamento de que a sentença não era contrária às leis nem à ordem pública francesas. Além disso, o Tribunal determinou que toda medida executória deveria sujeitar-se à uma autorização prévia do presidente do Tribunal.

Instado a se retratar sobre o conteúdo limitativo do exequatur, o Tribunal não mudou de opinião pois não Ihe parecia oportuno atentar contra a soberania de um Estado se não era imediatamente possível distinguir entre bens destinados a uma atividade soberana ou serviço público e aquelas provenientes de uma simples atividade econômica ou comercial de direito privado. $^{20}$

Em sede de recurso, a Corte de Apelação resolveu suprimir a parte do exequatur que condicionava toda medida concreta de execução à aprovação

\footnotetext{
${ }^{18}$ KNOEPFLER, F. L'immunité d'exécution contre les Etats. Revue de l'arbitrage, 2003, p. $1017,1039,1054$ e ss.

${ }^{19}$ Sentença de 8 de agosto de 1980. International Legal Materials 1981, p. 878 e ss.

20 Benvenuti et Bonfant S.A.R.L. C/ Gouvernement de la République du Congo, Tribunal de Grande Instance de Paris, decisão de 13 de janeiro de 1981. Journal du Droit International, 1981 , p. 365-370.
}

Revista Brasileira de Direito Internacional, Curitiba, v.2, n.2, jul./dez.2005 
do presidente do Tribunal ${ }^{21}$. A Corte julgou que o Tribunal, instado a reconhecer a sentença, não poderia se imiscuir na fase seguinte - de execução, momento no qual caber-se-ia indagar sobre a imunidade de execução do Estado estrangeiro. Esta decisão da Corte reconhece claramente os dois estágios pelos quais deve passar a sentença CIRDI na ordem interna reconhecimento e execução - a questão da imunidade de execução estatal só podendo ser invocada no segundo. O exequatur, explica a Corte, é somente um ato prévio às medidas de execução.

A decisão lembra também a força obrigatória da sentença CIRDI, mas ignora o fato de que o exequatur indevidamente faz menção à lei e ordem pública francesas. Como mencionamos acima, a referência a esses critérios não é admitida pela Convenção de Washington, segundo a qual o reconhecimento deve ser automático.

Apesar de ter obtido o reconhecimento da sentença, a empresa italiana não conseguiu executá-la. Foram penhorados os fundos de um banco francês (Crédit Lyonnais) de propriedade do Banco Comercial Congolês, cujo controle seria do governo do Congo. Mas a Corte Suprema julgou nula a penhora pois o banco não tinha a mesma personalidade jurídica do governo do Congo, e não poderia portanto responder pelos débitos estatais.

\section{(b) Liberian Eastern Timber Corporation (LETCO) X Libéria}

LETCO, uma empresa liberiana controlada por capital francês, obteve do United District Court for the Southern District of New York o reconhecimento de uma sentença do CIRDI que havia condenado a Libéria a pagar-Ihe um montante relativo à resolução prematura de um contrato de concessão ${ }^{22}$. Em seguida, a empresa obteve uma ordem de execução (writ of execution ${ }^{23}$ ) contra os bens da Libéria situados nos Estados Unidos. A República da Libéria pleiteou a anulação destas decisões alegando que as cortes americanas não

\footnotetext{
${ }^{21}$ Cour d'appel de Paris, decisão de 26 de junho de 1981. Journal du Droit International, p. 843 ss.

${ }^{22}$ Ex parte order de 5 de setembro de 1986. V. SCHREURER, C. Commentary on the ICSID Convention: article 54. ICSID Review - F.I.L.J., vol. 14, 1999, p. 94.

${ }^{23} 25$ de setembro de 1986. Idem, p. 95.
}

Revista Brasileira de Direito Internacional, Curitiba, v.2, n.2, jul./dez.2005 
teriam competência para reconhecer a sentença nem ordenar sua execução pois o Estado da Libéria não teria renunciado à sua imunidade de jurisdição e em conseqüência, segundo a lei americana Foreign Sovereign Immunities Act (FSIA), não poderia se sujeitar às cortes americanas. Em segundo lugar, o réu argumentou que os bens penhorados eram bens públicos e, devido à ausência de sua utilização para fins comerciais, seriam protegidos pela imunidade de execução segundo o $F S I A^{24}$

A District Court ${ }^{25}$ recusou o primeiro argumento afirmando que a adesão da Libéria à arbitragem CIRDI implicava, segundo o FSIA, uma renúncia à sua imunidade de jurisdição perante as cortes americanas. A motivação da Corte merece críticas, na medida em que a Convenção de Washington não admite o recurso a leis internas para o reconhecimento das sentenças que, relembramos, deve ser automático. Portanto a Corte não poderia ter baseado sua análise na lei americana FSIA. O recurso à tal lei deveria se restringir à fase executória, esta sim regida pelos direitos internos segundo a Convenção. ${ }^{26}$

O segundo argumento da Libéria (imunidade de execução) foi aceito pela Corte, a qual considerou que os bens designados (impostos e taxas de registro de navios da Libéria) sustentavam funções governamentais e não poderiam ser considerados como tendo uma natureza comercial. A exceção à imunidade de execução prevista pelo FSIA, portanto, não seria aplicável. Nesta linha, a Corte anulou a ordem de execução ${ }^{27}$, afirmando que a LETCO poderia pleitear a penhora de outros bens da Libéria utilizados para atividades comerciais.

De fato, após o insucesso da primeira tentativa de execução, a LETCO solicitou ao U.S. Court for the District of Columbia a penhora de contas

\footnotetext{
${ }^{24}$ FRANZONI, D. B. International law - Enforcement of International Centre for Settlement of Investment Dispputes Arbitral Awards in the United States - Signatories to the Convention on the Settlement of Investment Disputes Between States and Nationals of Other States are not entitled to sovereign immunity with respect to enforcement of ICSID arbitral awards, Liberian Eastern Timber Corp. v. Government of Republic of Liberia, 650 F. Supp. 73 (S.D.N.Y. 1986). Georgia journal of international and comparative law, vol. 18, 1988, p. 101-103.

${ }^{25}$ Decisão de 12 de dezembro de 1986, ver SCHREURER, op. cit., p. 95.

${ }^{26}$ Idem, p. 113-115.

${ }^{27}$ A U.S. Court of Appeals for the Second Circuit confirmou esta decisão em 19 de maio de 1987.
}

Revista Brasileira de Direito Internacional, Curitiba, v.2, n.2, jul./dez.2005 
bancárias da embaixada da Libéria. Entretanto, acatando a defesa da Libéria, a Corte rejeitou a execução sob o fundamento de que as contas bancárias da embaixada se beneficiariam da imunidade de execução prevista pela lei americana $(F S I A)$.

(c) Société Ouest Africaine des Bétons Industriels (SOABI) X República do Senegal

A Société Ouest Africaine de Bétons Industriels (SOABI) solicitou a execução na França de uma sentença CIRDI que condenou o Estado do Senegal a lhe pagar diversas somas a título de reparação de prejuízos sofridos em razão de uma rescisão unilateral de contratos concluídos entre ambos ${ }^{28}$. 0 Presidente do Tribunal de Grande Instância de Paris concedeu o exequatur mas este foi posteriormente cassado pela Corte de Apelação de Paris ${ }^{29}$. Baseando-se no artigo 1502, alinea 5, do Código de Processo Civil francês, a Corte considerou que a ordem de exequatur violava a ordem pública internacional pois ofendia o princípio da imunidade de execução que goza o Estado estrangeiro na França. A Corte afirmou que esta imunidade poderia ser descartada se os bens objeto da execução não tivessem uma destinação econômica ou comercial de direito privado, mas como a SOABI não estabelecera se a execução seria efetuada sobre este tipo de bens, a execução da sentença na França feriria a ordem pública internacional pois seria contrária ao princípio da imunidade.

BROCHES aponta que a Corte de Apelação errou em dois pontos. Primeiramente, ela ignorou o regime estabelecido pela Convenção de Washington, segundo o qual o direito interno (o Código de Processo Civil) não é aplicável na fase de reconhecimento da sentença arbitral; o papel do juiz nacional limita-se à verificação da autenticidade da cópia certificada da sentença. ${ }^{30} \mathrm{~A}$ Corte teria portanto ignorado o reconhecimento automático das

\footnotetext{
${ }^{28}$ Société Ouest Africaine des Bétons Industriels (SAOBI) c. République du Sénégal, sentença de 25 de fevereiro de 1988. Journal du Droit International, 1990, p. 191 e ss.

${ }^{29}$ Etat du Sénégal c/ Seutin, ès-qual. de liquidateur de la société SOABI, Cour d'appel de Paris (1re Ch. suppl.), decisão de 5 de dezembro de 1989. Revue de l'arbitrage, 1990, p. 164-175.

${ }^{30}$ Idem, p. 168 ss.
}

Revista Brasileira de Direito Internacional, Curitiba, v.2, n.2, jul./dez.2005 
sentenças CIRDI ao se utilizar de noções de ordem pública e do seu direito interno. Em segundo lugar, a Corte confundiu a fase de reconhecimento e a fase de execução, qualificando o exequatur de medida de execução. ${ }^{31}$ Ora, o princípio de imunidade de execução (e a natureza dos bens penhorados) só pode ser invocado na fase de execução, posterior ao procedimento de reconhecimento, o exequatur.

Este julgamento foi anulado pela Corte de Cassação ${ }^{32}$, que esclareceu a matéria. Primeiro, ela fez a distinção entre o exequatur e a fase de execução afirmando que o exequatur "não constitui, em si próprio, um ato de execução de natureza a provocar a imunidade de execução do Estado considerado"33. Após, ela aponta que "a Convenção de Washington de 1965 instituiu, nos seus artigos 53 e 54, um regime autônomo e simplificado de reconhecimento e de execução que exclui aquele dos artigos 1498 e seguintes do novo Código de Processo Civil e, em particular, as vias de recurso que este prevê " ${ }^{34}$. Assim, a decisão dissipa as confusões feitas pelo julgamento da instância inferior.

O exame da jurisprudência sobre a execução das sentenças CIRDI revela que, em relação à fase de reconhecimento, as jurisdições internas acabaram interpretando corretamente a Convenção de Washington, apesar das confusões iniciais. Relativamente à fase de execução propriamente dita, constata-se que a imunidade de execução do Estado estrangeiro continua a ser um grande empecilho. Existem duas saídas convencionais possíveis para esse problema: o exercício da proteção diplomática pelo Estado de nacionalidade do investidor estrangeiro (art. 27 da Convenção de Washington) e a apresentação de um pleito contra o Estado condenado perante a Corte Internacional de Justiça, alegando a violação de suas obrigações convencionais (art. 64): o descumprimento da sentença pelo Estado condenado implica a violação da Convenção, o que é um fato internacionalmente ilícito, resultando na responsabilidade internacional do Estado.

\footnotetext{
${ }^{31}$ Idem, ibidem.

32 Sté. SOABI c/ Etat du Sénégal, Cour de cassation, première chambre civile, decisão de 11 de junho de 1991, Journal du Droit International, 1991, p. 1005-1007.

${ }^{33}$ Idem, p. 1006.

34 Idem, ibidem.
}

Revista Brasileira de Direito Internacional, Curitiba, v.2, n.2, jul./dez.2005 
Neste ponto encontra-se uma diferença substancial entre as sentenças CIRDI e as sentenças arbitrais clássicas. Enquanto que a força obrigatória destas resulta da convenção das partes (cláusula ou compromisso arbitral), e restringe-se portanto à esfera contratual, a autoridade das sentenças CIRDI decorre de um tratado (a Convenção de Washington), o qual estipula a obrigação internacional de executar ${ }^{35}$. Isso explica por que o desrespeito desta obrigação acarreta conseqüências no plano da responsabilidade internacional estatal, diferentemente de uma sentença tradicional de arbitragem comercial internacional.

\section{CONCLUSÃO}

A despeito de ser um dos pilares da arbitragem internacional, pudemos verificar que o sistema da Convenção de Nova York limita a eficácia executória das sentenças, especialmente ao prever um mecanismo de controle da validade destas pelo juiz interno. A Convenção de Nova York, por sua vez, apesar de não resolver completamente os problemas relativos à execução de sentenças arbitrais contra Estados estrangeiros, prevê inegavelmente condições bem mais favoráveis que aquelas previstas pela Convenção de Nova York, especialmente no tocante ao reconhecimento automático das sentenças. Nesse sentido, ela poderia servir de inspiração para melhorias futuras no âmbito da arbitragem internacional, visando a aumentar a eficácia do sistema executório a fim de que a parte vencedora possa realmente obter a realização do direito que the foi reconhecido pela sentença.

Entretanto, não se deve olvidar que a diferença de tratamento decorre da natureza diferenciada das sentenças CIRDI. Sua força obrigatória é baseada diretamente na Convenção de Washington, ou seja, em um tratado internacional. Nesse sentido, o juiz interno não poderia questionar uma decisão cuja força obrigatória decorre do direito internacional; a violação deste direito acarreta conseqüências para o Estado na esfera da responsabilidade internacional.

${ }^{35}$ SANTULLI, Carlo. Droit du contentieux international. Paris: Montchrestein, 2005, p. 39.

Revista Brasileira de Direito Internacional, Curitiba, v.2, n.2, jul./dez.2005 


\section{REFERÊNCIAS}

BROTONS, A. R. La reconnaissance et l'exécution des sentences arbitrales étrangères. Recueil des cours, 1984, p. 169-350.

CARIAS-BORJAS, S. Recognition and enforcement of ICSID awards: the decision of the French Cour de cassation in SOABI v. Senegal. American review of international arbitration, vol. 2, n. 3, p. 354-372, 1991.

DELAUME, G. R. Reflections on the effectiveness of international arbitral awards. Journal of international arbitration, 1995, p. 5-19.

DELAUME, G. SEEE v. Yugoslavia: Epitaph or Interlude? Journal of International Arbitration, 1987, p. 25-43.

FRANZONI, D. B. International law - Enforcement of International Centre for Settlement of Investment Dispputes Arbitral Awards in the United States Signatories to the Convention on the Settlement of Investment Disputes Between States and Nationals of Other States are not entitled to sovereign immunity with respect to enforcement of ICSID arbitral awards, Liberian Eastern Timber Corp. v. Government of Republic of Liberia, 650 F. Supp. 73 (S.D.N.Y. 1986). Georgia journal of international and comparative law, vol. 18, p. 101-117, 1988.

GIARDINA, A. L'exécution des sentences du Centre international pour le règlement des différends relatifs aux investissements. Revue critique de droit international privé, 1982, p. 273-293.

KNOEPFLER, F. L'immunité d'exécution contre les Etats. Revue de l'arbitrage, 2003, p. 1017-1066.

LALIVE, J-F. Quelques observations sur l'immunité d'exécution des Etats et l'arbitrage international. In: International law at a time of perplexity: essays in honour of Shabtai Rosenne. Dordrecht/ Boston/ London: Martinus Nijhoff, 1989, p. 369-383.

RAMBAUD, P. Les suites d'un différend pétrolier: l'affaire Liamco devant le juge français. Annuaire Français de Droit International, 1979, p. 820-834.

SANTULLI, Carlo. Droit du contentieux international. Paris: Montchrestein, 2005.

SCHREURER, C. Commentary on the ICSID Convention: articles 53, 54, 55. ICSID Review - F.I.L.J., vol. 14, p. 46-158, 1999.

Revista Brasileira de Direito Internacional, Curitiba, v.2, n.2, jul./dez.2005 